\title{
A GESTÃO SECRETARIAL COMO PROPOSTA TEÓRICA: ELABORANDO O ESTADO DA QUESTÃO
}

\author{
SECRETARIAL MANAGEMENT AS A THEORETICAL \\ PROPOSAL: DEVELOPING THE STATE OF ISSUE
}

\section{LA GESTIÓN SECRETARIAL COMO PROPUESTA TEÓRICA: ELABORANDO EL ESTADO DE LA CUESTIÓN}

\author{
Conceição de Maria Pinheiro Barros \\ Doutora em Educação - Universidade Estadual \\ do Ceará, Fortaleza, Brasil \\ Professora Adjunta II - Universidade Federal do \\ Ceará, Fortaleza, Brasil \\ conceicaompb@ufc.br \\ Joelma Soares da Silva \\ Mestre em Administração - Universidade \\ Estadual do Ceará, Fortaleza, Brasil \\ Professora Adjunta I - Universidade Federal do \\ Ceará, Fortaleza, Brasil \\ joelma.soares@ufc.br

\section{Elaine Freitas de Sousa} \\ Doutora em Educação - Universidade Federal da \\ Paraíba, João Pessoa, Brasil \\ Professora Ajunta A - Universidade Federal do \\ Ceará, Fortaleza, Brasil \\ elainefreitas@ufc.br

\section{Francisco Edson Rodrigues da Silva} \\ Bacharel em Administração - Universidade \\ Estadual do Ceará, Fortaleza, Brasil \\ Servidor Técnico-administrativo em Educação - \\ Universidade Federal do Ceará, Fortaleza, Brasil \\ fedsonrsilva@hotmail.com
}

\author{
Contextus \\ ISSN 1678-2089 \\ ISSNe 2178-9258 \\ Organização: Comitê Científico Interinstitucional \\ Editor Científico: Diego de Queiroz Machado \\ Editor Executivo: Carlos Daniel Andrade \\ Avaliação: double blind review pelo SEER/OJS \\ Recebido em 01/08/2018 \\ Aceito em 19/08/2018 \\ $2^{a}$ versão aceita em 31/08/2018
}

\section{RESUMO}

A gestão secretarial é uma temática recorrente em estudos nacionais de Secretariado Executivo, porém ainda carente de comprovação científica. Este estudo tem como objetivo analisar as contribuições de pesquisas brasileiras para consubstanciar a gestão secretarial como proposta teórica. Metodologicamente, utilizou-se pesquisa do tipo Estado da Questão, fundamentada em Nóbrega-Therrien e Therrien (2010). Analisou-se o conteúdo de uma dissertação e de dezessete artigos nacionais. Após a análise, identificou-se que existem poucas investigações acerca do tema, evidenciando lacunas em relação à sua consolidação como área de conhecimento e ao estabelecimento tanto de seu objeto de estudo quanto de um arcabouço teórico-metodológico. As pesquisas denotam a interdisciplinaridade da área, mantendo um diálogo, principalmente, com a Administração. O Estado da Questão oportunizou ampla visão acerca da situação atual do conhecimento, dos principais enfoques de estudiosos e suas bases de sustentação teórica e empírica.

Palavras-chave: Gestão Secretarial; Estado da Questão; Teoria; Conhecimento; Secretariado Executivo.

\section{ABSTRACT}

Secretarial management is a recurring subject in national Executive Secretariat studies but still lacks scientific evidence. This study aims to analyze Brazilian researches' contributions to consolidate Secretarial Management 
as a theoretical proposal. Methodologically, the State of Issue research was used, which is based on NóbregaTherrien and Therrien (2010). The contents of one doctoral dissertation and of seventeen national articles were analyzed. As an outcome, few studies on the subject were identified, which is an evidence of gaps related to the consolidation of the knowledge area and to the establishment not only of its object of study but also of a theoreticalmethodological framework. The researches indicate how interdisciplinary the area is, since it keeps a dialogue mainly with management studies. The State of Issue provided a broad vision of: the current state of knowledge, the researchers' main approaches and their theoretical and empirical support basis.

Keywords: Secretarial Management; State of Issue; Theory; knowledge; Executive Secretariat.

\section{RESUMEN}

La gestión secretarial es un tema recurrente en los estudios nacionales de Secretariado Ejecutivo, pero todavía carente de evidencia científica. Este estudio tiene como objetivo analizar las contribuciones de investigaciones brasileñas para la consubstanciación de la gestión secretarial como una propuesta teórica. Metodológicamente, se utilizó la investigación Estado de Cuestión, basada en Nóbrega-Therrien y Therrien (2010). Se analizaron los contenidos de una tesis y de diecisiete artículos nacionales. Se identificó que existen pocos estudios sobre el tema, evidenciando una brecha relacionada con su consolidación como área de conocimiento y con el establecimiento no sólo de su objeto de estudio sino también de un marco teórico-metodológico. Las investigaciones denotan la interdisciplinariedad, manteniendo el diálogo, principalmente con la gestión. El Estado de Cuestión proporcionó una visión amplia: del estado actual del conocimiento, de los principales enfoques de los investigadores y de su base de apoyo teórico y empírico.

Palabras clave: Gestión Secretarial; Estado de Cuestión; Teoría; conocimiento; Secretariado Ejecutivo.

\section{INTRODUÇÃO}

As transformações no cenário organizacional ao longo das últimas décadas resultaram em mudanças no comportamento e na postura de profissionais de todas as áreas de conhecimento. O perfil dos secretários executivos, em consonância com tal realidade, passou por mudanças significativas nos últimos 30 anos. Enquanto, antes, sua atuação no contexto organizacional se restringia às funções técnicas, atualmente assume papel relevante para a atuação dos gestores, ao adotarem uma postura gerencial no seu campo de atuação (BARROS et al., 2013). Secretários executivos eficazes são aqueles com maior capacidade discricionária em seu papel (KAKABADSE; KHAN; KAKABADSE, 2016), que fomentam a comunicação interna e externa, bem como são habilitados a gerenciar pessoas e a conduzir processos (HALICI; YILMAZ; KASIMOĞLU, 2012).

Nesse sentido, Akpomi e Ordu (2009) definem um secretário como um assistente executivo que possui e demonstra a capacidade de assumir responsabilidades com ou sem supervisão, faz julgamentos e toma iniciativas e decisões no escopo da autoridade que lhe é atribuída. Isso significa que um secretário qualificado deve ter visão de negócios e conhecimentos amplos e versáteis que permeiam: contabilidade, gestão de pessoas, comunicação, prática de escritório e conhecimentos de todos os departamentos da organização em que está inserido. 
Por se tratar de formação universitária recente cujos estudos acadêmicos ainda são embrionários, percebe-se a carência de discussões científicas acerca das especificidades e contribuições culturais em cursos de Secretariado Executivo. Para compreender o surgimento e o crescimento do profissional da área, assim como de qualquer outra profissão, faz-se necessário conhecer o contexto histórico, buscando informações sobre a constituição social vigente, resgatando assim aspectos fundamentais como a política, a economia e a cultura.

Dentre as diversas transformações, a geração de conhecimento em Secretariado Executivo é uma das mais recentes e significativas. Mesmo com a evolução da formação e com o reconhecimento como área científica, o profissional ainda encontra restrições, principalmente, no campo da pesquisa e de publicações, o que acaba por dificultar o acesso às informações que possibilitem ampliar o conhecimento e consolidar uma identidade profissional própria.

Nesse contexto de adversidades, a área atualmente se define pela busca de uma identidade e legitimidade do seu objeto de estudo de maneira aprofundada e consistente, não apenas no campo pessoal por aqueles que a escolhem, mas também enquanto profissão valorizada e reconhecida, bem como enquanto área acadêmica dotada de fundamentos teóricos. Como parte fundamental do fortalecimento acadêmico da área, acredita-se que o debate é necessário e salutar.

Assim, propostas teóricas emergiram nos últimos anos e uma abordagem vem conquistando destaque: a gestão secretarial. Silva, Barros e Cruz (2016) alertam que, embora seja oficialmente conteúdo de formação específica na graduação e conteúdo da integralização curricular de pós-graduação, são poucos os estudos científicos que debatem a delimitação da gestão secretarial. Como resultado, uma profusão de assuntos é atribuída como pertinente à gestão secretarial. Segundo as autoras, esse cenário torna mais explícita uma lacuna que precisa ser preenchida ou ao menos, reduzida.

Com base em tais reflexões, esta investigação tem como questão norteadora: quais as contribuições da produção científica nacional de Secretariado Executivo para a gestão secretarial? Este estudo tem como objetivo analisar as contribuições de pesquisas brasileiras para a consubstanciação da gestão secretarial como proposta teórica.

Para tanto, foi realizado um estudo do tipo Estado da Questão (EQ) como parte de um projeto de pesquisa intitulado "Gestão secretarial e produção de conhecimento em Secretariado Executivo". Ressalta-se que a elaboração do Estado da Questão (EQ) se diferencia do Estado da Arte (EA). Nóbrega-Therrien e Therrien $(2004 ; 2010)$ esclarecem que o EQ faz uma busca 
seletiva e crítica de pesquisas próximas às especificidades do objeto investigado, o que requer exame de documentos fundamentais, enquanto o EA visa mapear a produção acadêmica utilizando, essencialmente, fontes em forma de resumos, utilizando-se de metodologia inventariante e descritiva acerca de um tema. Dessa forma, o EQ subsidia todo o processo de investigação, ajudando a redefinir os objetivos, auxiliando no planejamento do campo teóricometodológico, contribuindo para identificar categorias teóricas, para discutir e analisar dados, bem como para construir o conhecimento (NOBREGA-THERRIEN; THERRIEN, 2010; SILVEIRA; NOBREGA-THERRIEN, 2011).

Neste trabalho, o EQ teve como enfoque as pesquisas de dissertações e teses, bem como de artigos científicos nacionais, possibilitando uma visão crítica sobre o panorama das discussões acerca da gestão secretarial. Elegeu-se como bases de dados: o Catálogo de Teses e Dissertações da Coordenação de Aperfeiçoamento de Pessoal de Nível Superior (CAPES), o portal de periódicos da CAPES, revistas especializadas na área secretarial e qualificadas pela CAPES e anais de eventos científicos nacionais.

O artigo está divido em cinco seções, incluindo esta introdução. A segunda seção aborda a gestão secretarial como proposta teórica na área de Secretariado Executivo, a terceira apresenta a metodologia da pesquisa e a quarta versa sobre a análise e discussão dos resultados. Por fim, são apresentadas as conclusões.

\section{A GESTÃo SECRETARIAL COMO PROPOSTA TEÓRICA DO SECRETÁRIO EXECUTIVO}

Dado a atual posição do secretário executivo nas organizações, a gestão secretarial emerge como proposta de estudar o desenvolvimento das atribuições daquele profissional. Tema recorrente na literatura especializada recente (e.g. ALMEIDA; ROGEL; SHIMOURA, 2010; SILVA; BARROS; BARBOSA, 2012; LEAL; DAUMAL, 2014), a importância da gestão secretarial como nova possibilidade de estudo reside principalmente no fato de situar o secretário executivo como gestor de suas atribuições e tomador de decisões, contrariando a antiga visão do profissional unicamente executor.

Questionamentos acerca do assunto estão presentes em investigações, não somente pela observação empírica da atuação do secretário executivo, mas pelo próprio delineamento da sua formação acadêmica. Ressalte-se, ainda, o fato de as Diretrizes Curriculares Nacionais para o 
curso de Graduação em Secretariado Executivo preveem os estudos da Gestão Secretarial como conteúdo curricular específico (BRASIL, 2005). Em consonância, a avaliação do componente específico da área de Secretariado Executivo no Exame Nacional de Desempenho dos Estudantes (ENADE) engloba a gestão secretarial como um dos objetos de conhecimento a ser explorado para a realização da referida prova (BRASIL, 2018).

Contudo, a despeito de sua delimitação teórica, é evidente que a gestão secretarial ainda carece de parâmetros norteadores. Tal realidade é compreensível considerando-se o fato de ser uma proposta relativamente recente e que ainda necessita de aprofundamento. Sob esta ótica, Silva, Barros e Cruz (2016) apontam caminhos diversos utilizados pelos pesquisadores na tentativa de comportar uma multiplicidade de assuntos na abordagem da gestão secretarial. Tal movimento encontra amparo na visão de Cabral (1998) acerca da incompletude da pesquisa científica que conduz às várias formas de pensar sobre um mesmo tema. Na esteira do pensamento do autor, Silva e Roman Neto (2010, p. 83) afirmam que,

Os resultados de uma pesquisa suscitam questões adicionais que originam novas pesquisas para ratificar, refutar ou complementar as "visões Construídas", possibilitando o acúmulo de experiências e o avanço do conhecimento. Essa linha de pensamento vai ao encontro da difusão de uma perspectiva multiparadigmática, que permite uma visão circular pautada na contradição da convergência e na complementaridade, fundamentais na construção de uma teoria.

Acredita-se que a gestão secretarial tem sido naturalmente submetida a diferentes enfoques, mas que são olhares complementares, pois, na condição de teoria em construção, não pode ser estática nem unilateral. Nestas condições é preciso considerar a assertiva de Bicudo (2011, p. 13) sobre a busca pela construção do conhecimento teórico: "não se sustenta se o pensamento em processo for pautado por uma lógica linear”. É preciso pensá-la de forma plural considerando a interdisciplinaridade nata do Secretariado Executivo de modo a evitar visões pessoais calcadas como verdades absolutas, sob pena de empobrecê-la.

Considera-se ainda que, na atual conjuntura, estabelecer conceito para a gestão secretarial pode ser extemporâneo. Para Goode e Hatt (1979) muitos conceitos são estabelecidos unicamente com base em impressões sensoriais ou percepções próprias, porém, Matitz e Vizeu (2010) afirmam que um conceito só adquire significado dentro de um determinado sistema teórico. Na visão dos autores,

Conceitos podem criar problemas comunicativos quando um mesmo termo é utilizado simultaneamente por quadros de referência distintos [...] Conceitos podem variar em relação ao grau de "concretude" dos fenômenos aos quais fazem referência. Dessa forma, à ciência cabe a tarefa de relacionar com fecundidade o abstrato e o concreto, o geral e o específico, o abrangente e o restrito. Cabe à ciência, ainda, esclarecer 
conceitos que fazem parte da definição de outros conceitos, buscar a integração entre diferentes níveis teóricos, além de desenvolver os métodos apropriados de operacionalização e mensuração de conceitos (MATITZ; VIZEU, 2010, p. 3).

Ainda sobre a questão conceitual, Matitz e Vizeu (2010) asseveram que conceitos devem prestar-se à interpretação do empírico, e não o oposto. Portanto, novas situações e fenômenos não devem ser submetidos conceitos ortodoxos. Em outras palavras, é necessário respeitar as interações entre conceitos e realidade dos fatos, de forma a evitar distorções de significado e de representação simbólica (MATITZ; VIZEU, 2010).

Ao se pensar na gestão atribuída aos secretários executivos, têm-se ciência de que não se trata da mesma exercida por gestores de outras áreas, como no caso dos administradores, tendo em vista que na gestão secretarial, o objetivo principal ocorre pela ligação, transmissão, intermédio que acontece entre esse profissional e as demais esferas da organização. Como na estrutura das organizações encontram-se vários níveis hierárquicos, que abrangem desde o estratégico até o operacional, pela dinamicidade de transição com a qual esse profissional precisa se conectar a todos esses níveis, fica fácil perceber sua importância na disposição das relações que precisam ser firmadas neste âmbito, com o intuito de otimizar todas as atividades e práticas que norteiam e dão seguimento aos objetivos principais das empresas.

As discussões científicas acerca da gestão secretarial apontam para uma busca por caminhos capazes de delimitar a sua construção teórica. Evidencia-se o desenvolvimento de uma atuação, antes estritamente operacional, para o nível estratégico, por meio de competências técnicas, comportamentais (LEAL; DALMAU, 2014) e gerenciais (BARROS; BRAGA; SILVA, 2011; BARROS et al., 2013), denotando que as aptidões intrínsecas ao desempenho da gestão assemelham-se tanto para os profissionais com formação em administração e áreas afins como para os o secretário executivo (TAGLIARI; DURANTE, 2009).

O secretário tem sido reconhecido como gestor, por sua capacitação para atividades de gerenciamento (BECKER; CEOLIN, 2010); acredita-se que a administração deve gerar, indiscutivelmente, resultados relacionados aos objetivos de sua gestão (SANTOS et al., 2017), assim, o gestor secretarial deve oferecer respostas à empresa na qual está inserido. Este profissional tem sido identificado como aquele cuja atuação está voltada para as funções administrativa de planejar, organizar, dirigir e controlar, superando desafios, ampliando suas competências e sua área de inserção ao colaborar para o bom desempenho da organização (LASTA; DURANTE, 2008). 
Corroborando essa ideia, Barros, Silva e Ferreira (2015) propõem que gestão secretarial pode ser entendida como um processo administrativo que envolve atividades relativas às funções, aos papéis e às competências gerenciais e abrange, essencialmente, as áreas de atuação do secretário executivo.

Para tanto, utiliza-se de ferramentas e modelos de gestão (e.g. CALDAS; SANTOS, 2012; COSTA JÚNIOR; VALÉRIO; CANTAROTTI, 2017) que envolvem, entre outros, gestão de projetos (GONÇALVES; COSTA, 2016) e gestão por competências (WILLERS et al., 2015), de modo que as atividades desenvolvidas em sua área, ofereçam respostas às demandas da organização como um todo. Na opinião de Brun, Cechet e Neumann (2012), os resultados positivos desse processo dependem do controle emocional, tendo em vista que, muitas vezes, o secretário executivo trabalha sob pressão. A compreensão acerca da gestão secretarial, portanto, possui preponderância marcante nas teorias de gestão direcionadas tanto para atribuições específicas como generalistas (SILVA; BARROS; CRUZ, 2015).

Apesar dessas indicações conceituais, as quais posicionam o secretário no perfil de gestor, Silva, Barros e Barbosa (2012), chamam a atenção para o fato de que ainda há carência de investigações que possibilitem um aparato teórico-empírico que promova o delineamento do objeto de estudo do Secretariado Executivo, apesar dos avanços científicos nesse campo. Diante do exposto, salienta-se que a consolidação da gestão secretarial como teoria na área do Secretariado Executivo perpassa o debate acadêmico necessitando, antes de tudo, de pesquisas que comprovem cientificamente sua existência no cotidiano do profissional, ou mais ainda, verificar se ela ocorre nos parâmetros determinados hoje pela literatura ou necessita de ajustes de acordo com a realidade prática dos secretários executivos.

\section{METODOLOGIA}

Esta seção apresenta os procedimentos metodológicos da investigação e está organizado em duas subseções. A primeira faz o delineamento da pesquisa por meio de sua classificação, situando-a como um estudo do tipo EQ. Em seguida, apresenta o percurso da seleção dos trabalhos para este estudo e a técnica de análise desenvolvida. 


\subsection{Delineamento da pesquisa}

A presente pesquisa é de natureza qualitativa tendo em vista que envolve um processo reflexivo e analítico da realidade por meio de um método que possibilita a compreensão do objeto investigado (OLIVEIRA, 2010). Quanto aos objetivos, classifica-se como descritiva, ao analisar e descrever detalhadamente se apresenta o fenômeno pesquisado (OLIVEIRA, 2010).

No que se refere aos procedimentos técnicos, foi desenvolvido um levantamento bibliográfico baseado na consulta de livros, artigos e outras publicações sobre o tema proposto, seguido da construção do Estado da Questão (EQ).

A elaboração do EQ acerca da gestão secretarial é parte integrante de um projeto de pesquisa que visa estabelecer princípios para a instituição da gestão secretarial como construto do Secretariado Executivo; busca-se, portanto, contribuir para o delineamento de uma conceituação para a gestão secretarial.

De acordo com Nóbrega-Therrien e Therrien (2010) o objetivo do EQ é possibilitar ao pesquisador o registro sobre como se encontra o objeto investigativo, por meio de um rigoroso levantamento bibliográfico, no estado atual da ciência à sua disposição. Visa, também, a construção do rigor científico e a criticidade na imersão bibliográfica desenvolvida pelo pesquisador.

Nessa perspectiva, buscou-se desenvolver uma análise de pesquisas nacionais acerca da gestão secretarial por meio do rigor metodológico mediado pelo EQ, bem como uma visão analítica e crítica acerca das contribuições dessas investigações para o delineamento desse tema como um constructo. Nesse sentido, “o pesquisador, disposto a realizar o Estado da Questão de seu projeto de investigação, poderá exercer seu levantamento mediante vários meios possíveis de busca" (SILVEIRA; NÓBREGA-THERRIEN, 2011, p. 220).

Foi feito um levantamento de trabalhos no Catálogo de Teses e Dissertações da Coordenação de Aperfeiçoamento de Pessoal de Nível Superior (CAPES), portal de periódicos da CAPES, revistas especializadas na área secretarial e qualificadas pela CAPES e anais de eventos científicos nacionais.

As revistas identificadas foram: Gestão e Secretariado (Área de avaliação Administração, Ciências Contábeis e Turismo B2), Revista Capital Científico (Área de avaliação Administração, Ciências Contábeis e Turismo B3), Revista Expectativa (Área de 
avaliação Administração, Ciências Contábeis e Turismo B3), Gestão e Contabilidade da UFPI (Área de avaliação Administração, Ciências Contábeis e Turismo B4) e Secretariado Executivo em Revista (Área de avaliação Administração, Ciências Contábeis e Turismo B5).

Utilizou-se como descritores-chaves para a busca os termos exatos "Gestão Secretarial”, "Gestão e Secretariado" e "Competências Gerenciais" e Secret*. Esclarece-se que nos mecanismos virtuais de busca, deve-se utilizar aspas para indicar a busca de termos exatos e deve-se utilizar o sinal tipográfico asterisco (*) quando se busca termos com uma raiz semântica comum. Dessa forma, a busca utilizando o descritor "Competências gerenciais" e Secret*, retornou resultados que compreendiam o termo exato daquele entre aspas e também termos como secretariado, secretários, secretárias, secretarial, entre outros com a raiz "secret".

A seleção dos trabalhos para a construção do EQ baseou-se inicialmente nos títulos dos trabalhos, seguida da leitura dos resumos a fim de verificar se estes abordavam o tema em questão. Dessa maneira, foram destacados doze 10 artigos científicos publicados periódicos, sete artigos publicados em eventos científicos e uma dissertação, totalizando 18 trabalhos escolhidos para o diálogo acerca do delineamento do conceito de gestão secretarial.

A pesquisa foi realizada no período de junho a julho de 2018. O espaço temporal das publicações selecionadas foi definido após a conclusão da busca. Assim sendo, delimitou-se como interstício temporal, as publicações entre 2005 a 2018.

\subsection{A seleção das pesquisas sobre gestão secretarial}

A seleção das pesquisas a elaboração do EQ, iniciou-se com uma busca por trabalhos no portal de periódicos da CAPES e em revistas especializadas. Embora os resultados das buscas por artigos em periódicos apresentassem uma quantidade significativa de registos a maioria dos textos tratavam de assuntos que não tinham relação com o Secretariado Executivo ou abordavam a profissão não relacionando especificamente à Gestão Secretarial.

A maioria dos artigos discutiam temas relativos à gestão que fazem parte do cotidiano dessa profissão, como: gestão estratégica, administração do tempo, consultoria, empreendedorismo, tomada de decisões, gestão de conflitos, gestão da informação, tecnologia, comunicação, gestão de documentos, gestão do conhecimento, dentre outros. Considera-se que esses temas são relevantes para a pesquisa acerca da atuação do secretário executivo como 
Conceição de Maria Pinheiro Barros, Joelma Soares da Silva, Elaine Freitas de Sousa, Francisco Edson Rodrigues da Silva

gestor, entretanto, são insuficientes para apontar um caminho que aponte para a definição da gestão secretarial como um conceito ou teoria.

Dessa forma, a pesquisa nessas bases de dados retornou um total de 182 trabalhos, dos quais apenas vinte 20 tratavam realmente da temática gestão secretarial. Desses vinte trabalhos, foram selecionados dez, excluindo-se aqueles que se repetiam de uma base para outra. $\mathrm{O}$ resultado desta fase investigativa é apresentado no Quadro 1.

Quadro 1 - Síntese da busca por trabalhos no portal de periódicos da CAPES e em revistas científicas

\begin{tabular}{|c|c|c|c|c|c|}
\hline Descritores & Fonte & $\begin{array}{l}\text { Período } \\
\text { com } \\
\text { produções } \\
\text { registradas }\end{array}$ & $\begin{array}{l}\text { Trabalhos } \\
\text { registrados }\end{array}$ & $\begin{array}{c}\text { Trabalhos } \\
\text { sobre a } \\
\text { temática }\end{array}$ & $\begin{array}{c}\text { Trabalhos } \\
\text { selecionados }\end{array}$ \\
\hline \multirow[t]{6}{*}{$\begin{array}{l}\text { "Gestão } \\
\text { Secretarial" }\end{array}$} & $\begin{array}{l}\text { Portal de } \\
\text { Periódicos } \\
\text { CAPES }\end{array}$ & $2010-2018$ & 21 & 3 & 1 \\
\hline & $\begin{array}{l}\text { Revista } \\
\text { Gestão e } \\
\text { Secretariado }\end{array}$ & $2012-2016$ & 9 & 2 & 1 \\
\hline & $\begin{array}{l}\text { Revista } \\
\text { Capital } \\
\text { Científico }\end{array}$ & 2007 & 1 & 0 & 0 \\
\hline & $\begin{array}{l}\text { Revista } \\
\text { Expectativa }\end{array}$ & 2017 & 2 & 0 & 0 \\
\hline & $\begin{array}{l}\text { Secretariado } \\
\text { Executivo em } \\
\text { Revista }\end{array}$ & $2008-2017$ & 9 & 6 & 6 \\
\hline & $\begin{array}{l}\text { Revista de } \\
\text { Gestão e } \\
\text { Contabilidade } \\
\text { da UFPI }\end{array}$ & 2015 & 1 & 1 & 1 \\
\hline \multirow[t]{5}{*}{$\begin{array}{l}\text { "Gestão e } \\
\text { Secretariado" }\end{array}$} & $\begin{array}{l}\text { Portal de } \\
\text { Periódicos } \\
\text { CAPES }\end{array}$ & $2009-2018$ & 91 & 1 & 0 \\
\hline & $\begin{array}{l}\text { Revista } \\
\text { Gestão e } \\
\text { Secretariado }\end{array}$ & $2011-2016$ & 8 & 1 & 0 \\
\hline & $\begin{array}{l}\text { Revista } \\
\text { Capital } \\
\text { Científico }\end{array}$ & $2015-2018$ & 3 & 0 & 0 \\
\hline & $\begin{array}{l}\text { Revista } \\
\text { Expectativa }\end{array}$ & 2017 & 1 & 0 & 0 \\
\hline & $\begin{array}{l}\text { Secretariado } \\
\text { Executivo em } \\
\text { Revista }\end{array}$ & 2008 & 1 & 1 & 0 \\
\hline
\end{tabular}

(CONTINUA) 
(CONTINUAÇÃO)

\begin{tabular}{|c|c|c|c|c|c|}
\hline & $\begin{array}{l}\text { Revista de } \\
\text { Gestão e } \\
\text { Contabilidade } \\
\text { da UFPI }\end{array}$ & - & 0 & 0 & 0 \\
\hline \multirow[t]{6}{*}{$\begin{array}{l}\text { "Competências } \\
\text { gerenciais" e } \\
\text { Secret* }\end{array}$} & $\begin{array}{l}\text { Portal de } \\
\text { Periódicos } \\
\text { CAPES }\end{array}$ & $2005-2017$ & 30 & 1 & 0 \\
\hline & $\begin{array}{l}\text { Revista } \\
\text { Gestão e } \\
\text { Secretariado }\end{array}$ & 2013 & 1 & 1 & 0 \\
\hline & $\begin{array}{l}\text { Revista } \\
\text { Capital } \\
\text { Científico }\end{array}$ & 2018 & 1 & 0 & 0 \\
\hline & $\begin{array}{l}\text { Revista } \\
\text { Expectativa }\end{array}$ & 2011 & 1 & 1 & 1 \\
\hline & $\begin{array}{l}\text { Secretariado } \\
\text { Executivo em } \\
\text { Revista }\end{array}$ & 2009 & 1 & 1 & 0 \\
\hline & $\begin{array}{l}\text { Revista de } \\
\text { Gestão e } \\
\text { Contabilidade } \\
\text { da UFPI }\end{array}$ & 2015 & 1 & 1 & 0 \\
\hline Total & -- & - & 182 & 20 & 10 \\
\hline
\end{tabular}

Fonte: elaboração própria.

A segunda fase tomou como fonte de pesquisa os anais de eventos científicos nacionais da área secretarial. Foram eleitos os eventos Encontro Nacional Acadêmico de Secretariado Executivo (ENASEC), Encontro Nacional dos Estudantes de Secretariado Executivo (ENESEC) e Encontro de Estudos e Pesquisas em Secretariado Executivo (ENEPES) da Universidade Federal do Ceará (UFC). Os eventos ENASEC e ENECEC foram escolhidos por serem considerados com maior representatividade acadêmica nacionalmente. Optou-se, ainda, por buscar os trabalhos publicados no ENESEC por ser percebido como o principal evento científico e acadêmico da área no município de Fortaleza, Ceará.

O Quadro 2 demonstra os resultados obtidos da busca por trabalhos nos anais de eventos científicos nacionais da área secretarial. 
Conceição de Maria Pinheiro Barros, Joelma Soares da Silva, Elaine Freitas de Sousa, Francisco Edson Rodrigues da Silva

Quadro 2 - Síntese da busca por trabalhos nos anais de eventos científicos nacionais da área secretarial

\begin{tabular}{|c|c|c|c|c|c|}
\hline Descritores & Fonte & $\begin{array}{c}\text { Período com } \\
\text { produções } \\
\text { registradas } \\
\end{array}$ & $\begin{array}{c}\text { Trabalhos } \\
\text { registrados }\end{array}$ & $\begin{array}{c}\text { Trabalhos } \\
\text { sobre a } \\
\text { temática } \\
\end{array}$ & $\begin{array}{c}\text { Trabalhos } \\
\text { selecionados }\end{array}$ \\
\hline \multirow{3}{*}{$\begin{array}{l}\text { "Gestão } \\
\text { Secretarial" }\end{array}$} & ENASEC & 2015 e 2017 & 9 & 1 & 1 \\
\hline & ENESEC & $\begin{array}{l}2012,2016 \mathrm{e} \\
2017\end{array}$ & 13 & 6 & 3 \\
\hline & ENEPES & 2014 e 2017 & 2 & 2 & 2 \\
\hline \multirow{3}{*}{$\begin{array}{l}\text { "Gestão e } \\
\text { Secretariado" }\end{array}$} & ENASEC & 2015 e 2017 & 0 & 0 & 0 \\
\hline & ENESEC & $\begin{array}{l}2012,2016 \mathrm{e} \\
2017\end{array}$ & 0 & 0 & 0 \\
\hline & ENEPES & 2014 e 2017 & 0 & 0 & 0 \\
\hline \multirow{3}{*}{$\begin{array}{l}\text { "Competências } \\
\text { gerenciais" e } \\
\text { Secret* }\end{array}$} & ENASEC & 2015 e 2017 & 2 & 2 & 1 \\
\hline & ENESEC & $\begin{array}{l}2012,2016 \mathrm{e} \\
2017\end{array}$ & 1 & 0 & 0 \\
\hline & ENEPES & 2014 e 2017 & 0 & 0 & 0 \\
\hline Total & -- & -- & 27 & 11 & 7 \\
\hline
\end{tabular}

Fonte: elaboração própria.

Conforme Quadro 2, é interessante notar que os três eventos possuem Grupos de Trabalho (GT) específicos para a temática, o que denota uma tentativa de conferir visibilidade para essa área de pesquisa. $\mathrm{Na}$ busca em anais de eventos, o número de trabalho registrados com os descritores pesquisados foi menor do que aquele encontrado em bases de artigos e revistas especializadas. Entretanto, proporcionalmente, o número de trabalhos contabilizados é mais expressivo. Dos 11 trabalhos encontrados sobre a temática (o registro geral foi de vinte e sete trabalhos), sete foram contabilizados.

$\mathrm{Na}$ terceira etapa investigativa foi feito um levantamento de dissertações e teses nacionais sobre gestão secretarial no Catálogo de Teses e Dissertações da Coordenação de Aperfeiçoamento de Pessoal de Nível Superior (CAPES).

O Quadro 3 apresenta uma Síntese da busca por trabalhos no Catálogo de Teses e Dissertações da CAPES. 
Quadro 3 - Síntese da busca por trabalhos no Catálogo de Teses e Dissertações da CAPES

\begin{tabular}{|l|l|l|l|l|l|}
\hline \multicolumn{1}{|c|}{ Descritores } & \multicolumn{1}{|c|}{ Fonte } & $\begin{array}{l}\text { Período com } \\
\text { produções } \\
\text { registradas }\end{array}$ & $\begin{array}{l}\text { Trabalhos } \\
\text { registrados }\end{array}$ & $\begin{array}{c}\text { Trabalhos } \\
\text { sobre a } \\
\text { temática }\end{array}$ & $\begin{array}{c}\text { Trabalhos } \\
\text { selecionados }\end{array}$ \\
\hline $\begin{array}{l}\text { "Gestão } \\
\text { Secretarial" }\end{array}$ & $\begin{array}{l}\text { Catálogo de } \\
\text { Teses e } \\
\text { Dissertações } \\
\text { da CAPES }\end{array}$ & 2013 & 1 & 1 & 1 \\
\hline $\begin{array}{l}\text { "Gestão e } \\
\text { Secretariado" }\end{array}$ & $\begin{array}{l}\text { Catálogo de } \\
\text { Teses e } \\
\text { Dissertações } \\
\text { da CAPES }\end{array}$ & -- & 0 & 0 & 0 \\
\hline $\begin{array}{l}\text { "Competências } \\
\text { Secret* }\end{array}$ & $\begin{array}{l}\text { Catálogo de } \\
\text { Teses e } \\
\text { Dissertações } \\
\text { da CAPES }\end{array}$ & -- & 0 & 0 & 0 \\
\hline Total & -- & - & 1 & 1 & 1 \\
\hline
\end{tabular}

Fonte: elaboração própria.

De acordo com o Quadro 3, nesta fase, foi identificado apenas um trabalho, especificamente para o descritor "Gestão Secretarial”. O trabalho foi contabilizado, pois não havia sido registrado em nenhuma das buscas anteriores.

Percebeu-se que nas pesquisas de Pós-Graduação Stricto Sensu existe preocupação com temas relacionados à profissão, tais como: condições de trabalho, informação, línguas, educação, atuação no setor público, identidade profissional. Esses trabalhos não foram selecionados visto que para a elaboração do EQ deve-se realizar uma busca seletiva e crítica das pesquisas científicas limitando-se aos estudos que interessam ao pesquisador (NÓBREGATHERRIEN; THERRIEN, 2010). No caso deste trabalho, o interesse gira em torno do objeto de estudo de um projeto de pesquisa: o delineamento do conceito de gestão secretarial. Acredita-se que ausência de pesquisa Stricto Sensu acerca do tema se deve ao fato de não existir programa de pós-graduação em Secretariado Executivo no Brasil.

A interpretação desta pesquisa teve como técnica a análise de conteúdo a qual conforme Bardin (2009, p. 27) “[...] observa com interesse as tentativas que se fazem no campo alargado da análise de comunicações: lexicometria, enunciação linguística, análise de conversação, documentação e base de dados [...]". Nessa perspectiva, buscou-se identificar convergências e diferenças entre as abordagens feitas nas pesquisas. 


\section{ANÁLISE E DISCUSSÃO DOS RESULTADOS}

Esta seção apresenta a elaboração do EQ sobre gestão secretarial, por meio do levantamento das teorias utilizadas para fundamentar os artigos, os enfoques das pesquisas e suas contribuições para o objeto investigado: o delineamento do conceito de gestão secretarial. Para tanto, está dividida em duas partes: principais enfoques e teorias abordadas nas pesquisas acerca da gestão secretarial e as abordagens das pesquisas acerca de gestão secretarial. É relevante esclarecer que, neta fase, para a elaboração do EQ, foi realizada a leitura completa dos textos selecionados, buscando aproximação das pesquisas com o objeto de estudo desta proposta.

\subsection{Principais enfoques e teorias abordadas nas pesquisas acerca da gestão secretarial}

Os títulos dos trabalhos envolvem a utilização de ferramentas e modelos de gestão na área secretarial, o secretário como gestor, fundamentação da gestão secretarial, competências, funções e atividades do gestor secretarial.

O Quadro 4 expressa os dados básicos dos trabalhos selecionados para a construção do Estado da Questão acerca da Gestão Secretarial.

Quadro 4 - Dados básicos dos trabalhos selecionados para o Estado da Questão

\begin{tabular}{|l|l|l|}
\hline Título do trabalho & Publicação & Ano \\
\hline $\begin{array}{l}\text { As ferramentas da análise SWOT e ciclo } \\
\text { PDCA implantadas no contexto da gestão } \\
\text { secretarial }\end{array}$ & $\begin{array}{l}\text { Secretariado Executivo em } \\
\text { Revista }\end{array}$ & 2017 \\
\hline $\begin{array}{l}\text { Secretário executivo na gestão: evidências } \\
\text { empíricas }\end{array}$ & ENEPES & 2017 \\
\hline $\begin{array}{l}\text { A gestão de projetos para o profissional de } \\
\text { Secretariado }\end{array}$ & ENESEC & 2016 \\
\hline $\begin{array}{l}\text { O que você compreende por Gestão } \\
\text { Secretarial? }\end{array}$ & ENASEC & 2015 \\
\hline $\begin{array}{l}\text { Mapeamento de competências: mensurando a } \\
\text { competência gerencial no desempenho do } \\
\text { trabalho de secretários executivos em cargos } \\
\text { de chefia numa instituição de ensino superior }\end{array}$ & ENASEC & 2015 \\
\hline $\begin{array}{l}\text { Gestão Secretarial: delineando atividades, } \\
\text { funções e competências gerenciais }\end{array}$ & $\begin{array}{l}\text { Revista de Gestão e } \\
\text { Contabilidade da UFPI }\end{array}$ & 2015 \\
\hline
\end{tabular}




\section{(CONTINUAÇÃO)}

\begin{tabular}{|c|c|c|}
\hline $\begin{array}{l}\text { Cenário do ensino da Gestão Secretarial em } \\
\text { cursos de graduação na área de Secretariado } \\
\text { Executivo no Brasil }\end{array}$ & ENEPES & 2014 \\
\hline $\begin{array}{l}\text { As competências gerenciais desenvolvidas } \\
\text { pelos secretários executivos }\end{array}$ & $\begin{array}{l}\text { Revista de Gestão e } \\
\text { Secretariado }\end{array}$ & 2013 \\
\hline $\begin{array}{l}\text { A Gestão Secretarial na perspectiva da ética } \\
\text { discursiva }\end{array}$ & $\begin{array}{l}\text { Catálogo de Teses e } \\
\text { Dissertações da CAPES }\end{array}$ & 2013 \\
\hline $\begin{array}{l}\text { As ferramentas da prática da gestão } \\
\text { secretarial utilizadas pelos profissionais de } \\
\text { secretariado executivo egressos da } \\
\text { Universidade do Estado do Pará }\end{array}$ & $\begin{array}{l}\text { Secretariado Executivo em } \\
\text { Revista }\end{array}$ & 2012 \\
\hline $\begin{array}{l}\text { A evolução das técnicas secretariais e da } \\
\text { gestão secretarial }\end{array}$ & ENESEC & 2012 \\
\hline $\begin{array}{l}\text { Fundamentação da Gestão Secretarial: um } \\
\text { estudo bibliométrico }\end{array}$ & $\begin{array}{l}\text { Revista de Gestão e } \\
\text { Secretariado }\end{array}$ & 2012 \\
\hline $\begin{array}{l}\text { Gestão secretarial: a evolução das funções do } \\
\text { profissional de secretariado e a efetividade da } \\
\text { inteligência emocional nos processos de } \\
\text { trabalho }\end{array}$ & $\begin{array}{l}\text { Secretariado Executivo em } \\
\text { Revista }\end{array}$ & 2012 \\
\hline $\begin{array}{l}\text { Uma análise de ferramentas de prática da } \\
\text { gestão secretarial }\end{array}$ & ENESEC & 2012 \\
\hline $\begin{array}{l}\text { As competências gerenciais na atuação do } \\
\text { secretário executivo no nível estratégico }\end{array}$ & Revista Expectativa & 2011 \\
\hline $\begin{array}{l}\text { Gestão Secretarial - uma nova visão de } \\
\text { assessoramento nas organizações }\end{array}$ & $\begin{array}{l}\text { Secretariado Executivo em } \\
\text { Revista }\end{array}$ & 2010 \\
\hline $\begin{array}{l}\text { Gestão Secretarial: semelhanças entre } \\
\text { competências gerenciais e secretariais }\end{array}$ & $\begin{array}{l}\text { Secretariado Executivo em } \\
\text { Revista }\end{array}$ & 2009 \\
\hline $\begin{array}{l}\text { A Gestão Secretarial no cenário } \\
\text { organizacional contemporâneo }\end{array}$ & $\begin{array}{l}\text { Secretariado Executivo em } \\
\text { Revista }\end{array}$ & 2008 \\
\hline
\end{tabular}

Fonte: elaboração própria.

Conforme se observa no Quadro 4 há uma evolução na quantidade de publicações acerca da gestão secretarial, tendo maior número de trabalhos divulgados em 2012. Porém, esse quantitativo ainda é incipiente para a busca de subsídios teóricos e empíricos que possibilitem a consolidação desse tema. Exemplificando a carência, pode-se ressaltar o fato de que somente uma pesquisa de pós-graduação, aborda especificamente a gestão secretarial.

Após a leitura dos trabalhos mencionados no Quadro 4 procedeu-se a análise dos principais aspectos das pesquisas. Percebe-se que um dos enfoques das pesquisas é o questionamento acerca da gestão como uma atribuição do profissional secretário e se esse profissional está preparado para ser um gestor. Busca-se, assim, identificar atribuições e competências do secretário relacionando-as à gestão na área secretarial (TAGLIARI; DURANTE, 2009). Lasta e Durante (2008) buscaram interpretar se o secretário executivo pode 
ser concebido como um gestor, tendo como base as suas atividades e/ou funções. Em sua investigação identificaram os seguintes aspectos de gestão na atuação do secretário executivo: planejamento, organização, tomada de decisões, gerenciamento de conflitos, condução e acompanhamento de pessoas, negociação. Observa-se as pesquisas apresentam aspectos relacionados à gestão na área secretarial, os quais permitem situar o secretário executivo como gestor. Montenegro e Durante (2017) contribuem para essa percepção ao verificarem a participação do secretário executivo nos processos de gestão.

O estudo de Becker e Ceolin (2010, p. 2) parte da problemática acerca dos fatores que “[...] contribuem para a transformação de perfil secretarial tático/prático, para tornar-se um profissional que atua como gestor estratégico dos seus processos de trabalho [...]”. Observa-se o empenho das pesquisas em busca de subsídios que colaborem para a percepção do secretário como gestor. Colabora para essa discussão o texto de Paes e Mercês (2012) ao discutir a evolução das técnicas secretariais e da gestão secretarial.

As competências do secretário relacionando-as ao gerenciamento na atuação desse profissional apresenta-se como uma linha de pensamento em busca do delineamento da gestão secretarial (TAGLIARI; DURANTE, 2009, BARROS; BRAGA; SILVA, 2011). O estudo de Barros, Silva e Ferreira (2015) corrobora a percepção de que o gestor secretarial necessita desenvolver competências gerenciais e faz um delineamento das suas atividades, bem como da abrangência de sua atuação. Destaca-se, também, a pesquisa de Willers et al. (2015) ao identificarem as competências gerenciais no trabalho de secretários executivos que ocupam cargos de chefia em instituição de ensino.

Outra perspectiva dos estudos refere-se às ferramentas e modelos de gestão na atuação secretarial. Sobre esse aspecto Caldas e Santos (2012) preocuparam-se em estudar a utilização das ferramentas da prática da gestão secretarial no âmbito organizacional pelos secretários executivos. Costa Júnior, Valério e Cantarotti (2017) consideram as ferramentas de análise baseadas na sigla SWOT (strengths, weaknesses, opportunities, threats) no contexto secretarial. Estes estudos denotam que, para atuar como gestor, o secretário executivo precisa conhecer diferentes ferramentas administrativas. Gonçalves e Costa (2016) situam o secretário executivo na gestão de projetos, fazendo um paralelo entre as competências secretariais e do gestor de projetos. Tais estudos denotam que para atuar no como gestor, o secretário executivo precisa conhecer e executar formas de gestão contemporânea. 
Silva, Barros e Barbosa (2012) realizaram um estudo bibliométrico no qual foram identificados os principais assuntos que embasam a gestão secretarial, concluindo que existe uma diversidade de temas em torno dessa temática, tais como: qualidade, liderança, sustentabilidade. As citadas autoras, alertam para o fato de não terem encontrado uma teoria capaz de nortear o tema. Silva, Barros e Cruz (2015) consideram a percepção de discentes acerca da gestão secretarial, como relevante para a o embasamento e para a constituição desse conceito. A fundamentação da gestão secretarial é investigada, ainda, com base no cenário do ensino, conforme pesquisa de Santos e Silva (2014). Este enfoque, indica que a gestão secretarial é um assunto presente na formação do secretário executivo, criando espaço para o aprofundamento de proposições que possibilitem a sua construção como área acadêmica.

Brun, Cechet e Neumann (2012, p. 36) visam "promover a análise das funções secretariais, relacionando-as com as mudanças provindas ao longo dos tempos". Apresentam uma retrospectiva das atividades secretariais e analisam a inteligência emocional como fator importante para o exercício profissional. Silva (2013) propõe a ética do Discurso em Habermas (1983) na gestão de secretaria.

No que se refere às principais teorias que fundamentam as investigações acerca do tema, foram considerados os autores de referência das áreas com as quais as pesquisas em Secretariado Executivo dialogam. O Quadro 5 destaca a relação entre as principais teorias e os autores utilizados na fundamentação das pesquisas.

Quadro 5 - Relação entre principais teorias e autores utilizados na fundamentação das pesquisas

\begin{tabular}{|c|c|}
\hline Principais abordagens teóricas & Principais teóricos \\
\hline $\begin{array}{l}\text { Competências gerenciais, papéis gerenciais, } \\
\text { modelos gerenciais, aprendizado gerencial e } \\
\text { competências gerenciais }\end{array}$ & $\begin{array}{l}\text { Motta (2004), Quinn et al. (2003), Ruas } \\
\text { (2000), } \\
\text { Fleury e Fleury (2001), Dutra (2010), } \\
\text { Brandão (2009; 2012). }\end{array}$ \\
\hline Gestão & Motta (1999), Robbins (2000) \\
\hline $\begin{array}{l}\text { Administração Científica de Taylor, funções } \\
\text { administrativas }\end{array}$ & Fayol (1990) \\
\hline Modelos de gestão & Fischimann (2009); \\
\hline Inteligência emocional & Goleman (1995) \\
\hline Ética do discurso & Habermas (1983) \\
\hline
\end{tabular}

Fonte: elaboração própria. 
Ressalta-se que para este EQ foram consideradas as principais as proposições teóricas abordadas nos artigos selecionados, no intuito de manter o rigor deste tipo de estudo em busca de aproximação com o objeto investigativo. Assim, foram destacados no Quadro 5 as principais bases teóricas e seus respectivos estudiosos que foram consideradas como relevantes para o diálogo com a gestão secretarial.

Um dos enfoques teóricos recorrentes nos estudos é a busca por competências gerenciais do secretário executivo. Nesse intuito, utiliza-se como fundamento a proposta de Quinn et al. (2003) focalizando os modelos gerenciais (TAGLIARI; DURANTE, 2009), papéis e competências gerenciais (BARROS; BRAGA; SILVA, 2011, BARROS et al., 2013). Do mesmo modo, as competências gerenciais têm como base teórica principal as proposições de Quinn et al. (2003) na investigação de Barros, Silva e Ferreira (2015), considerando-se os oito papéis dos gerentes, a saber: diretor; produtor, monitor, coordenador, facilitador, mentor, inovador e negociador. Na concepção de Willers et al. (2015), as competências gerenciais do secretário executivo possuem como embasamento teórico método de mapeamento de competências proposto por Brandão (2009; 2012).

O estudo de Barros, Braga e Silva (2011) fundamentam sua pesquisa no conceito de competência definido de Dutra (2010) como uma característica subjacente a um indivíduo que é casualmente relacionada com desempenho superior na realização de uma atividade e no conceito de Fleury e Fleury (2001, p. 184) de que o conceito de competência é usado para" [...] designar pessoa qualificada para realizar algo. Portanto se afirma que competência é a capacidade de um indivíduo de realizar algo com eficiência”. Fleury e Fleury (2001) consideram que competência é um conjunto de conhecimentos, habilidades e atitudes que explicam uma alta performance. Ao investigarem as competências do secretário executivo no nível estratégico Barros, Braga e Silva (2011) têm como fundamentação teórica, entre outros autores, Oliveira (2006), destacando os níveis estratégico, tático e operacional ao considerarem que "para que o processo organizacional aconteça de forma eficaz é necessário considerar aspectos como, a estrutura organizacional e as rotinas e procedimentos administrativos" (BARROS; BRAGA; SILVA, 2011, p. 94).

As pesquisas empenham-se em situarem o secretário executivo como gestores. Nesse intento, Becker e Ceolin (2010) dialogam com Motta (1999) ressaltando o gerenciamento como uma arte mediada pela interação com as pessoas para pensar, decidir e agir. Ao situarem o secretário no âmbito da gestão, as pesquisas Tagliari e Durante (2009) apresentam a percepção de Motta (2004) ao salientar as quatro grandes áreas do conhecimento administrativo essenciais 
na formação de dirigentes: estratégia, racionalidade administrativa, liderança e habilidades interpessoais, processo decisório. Considera, ainda, as proposições de Ruas (2000), Quinn et al. (2003) e Motta (2004) afirmando que fazem uma definição de profissionais que atuam na gestão e suas características básicas, agrupadas em: visão estratégica, planejamento, organização, controle, liderança, comunicação, trabalho em equipe, motivação, processo decisório, negociação, proatividade, criatividade, flexibilidade e competência interpessoal.

Salienta-se, ainda, a Administração Científica (FAYOL, 1990) como embasamento para as pesquisas analisadas. Nesse sentido, Barros, Silva e Ferreira utilizam como teoria principal as funções administrativas para identificar as atividades do gestor secretarial. Complementando essa ideia, Becker e Ceolin (2010) também abordam as funções de planejamento, liderança e controle amparados em Robbins (2000). Com relação às atividades do secretário como gestor, tendo como alicerce o processo administrativo, Barros, Silva e Ferreira (2015) relacionaram na função planejamento: participação no planejamento da organização, planejamento de eventos da organização, planejamento da área específica de atuação secretarial, planejamento e gestão de rotina administrativa; na organização: organização de eventos, métodos, processos e atividades da organização e da área secretarial, distribuição de atividades, gestão de informação, documentos, materiais e processos; direção: orientação de atividades secretariais, influenciar pessoas para o alcance de objetivos, liderança, supervisão na área secretarial; controle: participação na avaliação organizacional, acompanhamento do planejamento da área de atuação secretarial, avaliação de desempenho, controle de qualidade. Fortalecendo essa discussão, Montenegro e Durante (2017) apresentam como resultados empíricos indicações de gestão por meio de atividades como: gerenciar informações e documentos; tomar decisões setoriais e/ou organizacionais; gerir conflitos, comandar funcionários, solucionar problemas.

Busca-se, também, como caminho direção da constituição teórica da gestão secretarial, a contextualização de sua atuação de modelos de gestão. Nessa linha de pensamento, encontrase o trabalho de Costa Júnior, Valério e Cantarotti (2017), o qual estuda a análise SWOT e o ciclo PDCA no contexto da gestão organizacional a luz de Fischimann (2009) considerando essa análise é uma ferramenta de planejamento estratégico, a qual cuja técnica administrativa possibilita a análise do ambiente organizacional, cria a compacidade das oportunidades e ameaças.

No entendimento de que a gestão secretarial se pauta no conceito de inteligência emocional. Para isso, apoiam-se em Goleman (1995) que aponta a importância da inteligência emociona no ambiente de trabalho para que haja motivação, controle de impulsos e empatia. 
Esses aspectos emocionais podem ser considerados no trabalho secretarial, principalmente, pelo fato de que este profissional necessita desenvolver relações interpessoais com os demais funcionários nos diversos níveis de uma organização. A proposta de Silva (2013) também perpassa as relações dose secretários com os demais colaboradores, entretanto, propõe como caminho as relações alicerçadas na ética do Discurso segundo Habermas (1983) a qual significa a possibilidade de se apresentar razões em um ambiente favorável a criticidade, ao questionamento.

Observa-se que as pesquisas analisadas buscam fundamentação teórica em estudiosos e teorias de diversas áreas, especialmente, da Administração, desenvolvendo um diálogo com esses autores e relacionando as suas propostas à atuação do secretário executivo a fim de indicar um aporte que contribua para a delimitação do conceito de gestão secretarial. Essas abordagens denotam a interdisciplinaridade da área secretarial. As teorias que fundamentam a gestão secretarial fortalezam a ideia de Nascimento (2012) ao refletir que o Secretariado Executivo se ancora em conhecimentos de outras áreas, como a Administração e Sociologia, entre outras.

\subsection{Abordagens das pesquisas acerca da gestão secretarial}

A análise das pesquisas científicas selecionadas para a construção do EQ possibilitou apreender suas principais contribuições para delinear a gestão secretarial. Os delineamentos da gestão secretarial focalizados nas pesquisas são expostos no Quadro 6.

Quadro 6 - Abordagens da gestão secretarial

\begin{tabular}{|l|l|}
\hline Abordagens da gestão secretarial & Autores \\
\hline $\begin{array}{l}\text { Competências do secretário executivo } \\
\text { relacionadas à gestão }\end{array}$ & $\begin{array}{l}\text { Tagliari e Durante (2009), Barros, Braga e } \\
\text { Silva (2011), Barros et al. (2013), Barros, } \\
\text { Silva e Ferreira (2015). }\end{array}$ \\
\hline Gestão para assessoria & $\begin{array}{l}\text { Becker e Ceolin (2010), Caldas e Santos } \\
(2012)\end{array}$ \\
\hline O secretário como gestor & $\begin{array}{l}\text { Lasta e Durante (2008), Becker e Ceolin } \\
(2010)\end{array}$ \\
\hline $\begin{array}{l}\text { Atividades do secretário executivo relacionadas } \\
\text { às funções administrativas }\end{array}$ & Barros, Silva e Ferreira (2015) \\
\hline $\begin{array}{l}\text { Gestão secretarial por meio da inteligência } \\
\text { emocional }\end{array}$ & Brun, Cechet e Neumann (2012) \\
\hline $\begin{array}{l}\text { Secretário como gestor do conhecimento e de } \\
\text { relacionamento }\end{array}$ & Silva (2013) \\
\hline
\end{tabular}

Fonte: elaboração própria. 
Nesta fase da análise, são destacadas as principais abordagens acerca da gestão secretarial que contribuem para a sua consubstanciação. Com base nas abordagens destacadas no Quadro 6, observam-se estudos que delineiam a gestão secretarial a partir das competências do secretário executivo relacionando-as às aptidões de gestão e gerenciamento. Tagliari e Durante (2009, p. 14) afirmam que “[...] as competências necessárias para o desempenho da gestão são muito semelhantes tanto para os profissionais com formação em administração ou áreas afins como para os profissionais secretários executivos”.

Barros, Braga e Silva (2011, p. 103-104) ao pesquisarem as competências gerenciais desenvolvidas pelos secretários executivos analisaram que existe uma relação com a postura desse profissional relacionada aos seguintes aspectos: "pensamento estratégico, empreendedorismo, tomadas de decisões, comunicação, trabalha em equipe, orientação para o cliente, inovação e criatividade, entre outras competências estão sendo inseridas na profissão de secretariado executivo".

Complementando a ideia de que as competências gerenciais são necessárias à gestão secretarial, Barros et al. (2013) refletem que as mesmas estão presentes nas diversas atribuições do secretário de modo que contribuam para o alcance dos objetivos organizacionais. Segundo esse estudo tais competências, são principalmente:

[...] a compreensão de si mesmo e dos outros, a comunicação eficaz, a construção de equipes, a administração de informações por meio de pensamento crítico e a coordenação de projetos e/ou eventos. Estão presentes, ainda, na atuação secretarial: o planejamento e organização relativos aos serviços de secretaria; o estabelecimento de metas e objetivos relacionados ao trabalho em equipe; a administração do tempo e do estresse, além da contribuição nas negociações de acordos e compromissos, por meio da apresentação de ideias, sugestões e opiniões, para tomada de decisão em reuniões com pares e subordinados. Destacam-se, também, as competências relativas ao pensamento criativo ao buscarem a inovação dos processos de trabalho e convívio e gerenciamento da mudança (BARROS et al., 2013, p. 45).

Outra abordagem das pesquisas analisadas é a percepção de que o secretário atua como assessor da gestão organizacional. Essa visão é compartilhada por Becker e Ceolin (2010) ao afirmarem que o profissional de Secretariado assumiu papel direcionado à área gerencial, intervindo nas atividades das pessoas e obtendo controle sobre setores e conhecimento dos processos de trabalho. Citam, ainda que o secretário executivo "é um profissional preparado para assessorar e articular o nível estratégico da organização. Por isso é considerado um elo entre a empresa e seus clientes internos e externos" (BECKER; CEOLIN, 2010, p. 13). 
Caldas e Santos (2012) também associam a gestão secretarial à atividade de assessoria onde o secretário executivo presta assessoramento a executivos e colabora para as funções gerenciais e procedimentos administrativos. Os citados autores concluem que a gestão secretarial é fundamental para a práxis em assessoria, a gestão secretarial é primordial para o desenvolvimento da práxis em assessoria executiva e seus conceitos estão firmados no fazer e no saber dos assessores (CALDAS; SANTOS, 2012).

Percebe-se que esta concepção converge na compreensão da gestão secretarial como um aspecto da assessoria. No que se refere a esse pressuposto considera-se relevante que se faça uma reflexão sobre os conceitos de gestão e assessoria, a fim de que se esclareçam as diferenças entre seus significados e sua abrangência. Ressalta-se que gestão é o "ato ou efeito de gerir" FERREIRA, 2001, p. 374) e significa ter gerência sobre algo, administrar negócios, recursos e pessoas. A gestão é exercida por profissionais das diversas áreas que possuem conhecimentos específicos visando o desenvolvimento das atividades de uma área. Essa função requer o desenvolvimento do processo administrativo: planejamento, organização, liderança, controle e tomada de decisões (Quinn et al. 2003).

O gestor, de acordo com Maximiano (2004) é o indivíduo que atua do processo administrativo com o intuito de alcançar os objetivos de uma empresa. Por outro lado, assessoria está relacionada à prestação de assistência a um gestor, facilitando o desenvolvimento de suas funções; no âmbito secretarial, trata-se de uma das formas de atuação, assim como consultoria; gestão e empreendedorismo (LEAL; DALMAU, 2014). Considerando-se as diferenças existentes entre os conceitos de gestão e assessoria, alerta-se que é fundamental o aprofundamento teórico e empírico acerca dessa proposição a fim de que se esclareça essa relação no âmbito da gestão secretarial.

Em outra linha de pensamento, alguns trabalhos apontam o secretário como gestor. Para Lasta e Durante (2008, p. 6) o secretário executivo insere-se no âmbito organizacional atuando como gestor e contribuindo para o seu crescimento destacando ainda que esse profissional toma decisões, possui capacidade técnica e humana, poder de liderar e desenvolve atividades de gestão. Do mesmo modo, Becker e Ceolin (2010) consideram que o gestor secretarial agrega valor à organização e colabora para o alcance dos objetivos e acrescentam que a gestão está inserida no contexto secretarial, visto que o secretário executivo possui características relacionadas à área, como tomada de decisões e criatividade. 
Outra contribuição para o delineamento da gestão secretarial é a busca por identificação das atividades desenvolvidas pelo secretário executivo que envolvem aspectos de gestão. Nessa direção, as pesquisas de Barros et al. (2013) e Barros, Silva e Ferreira (2015) identificaram as atividades de gerenciamento realizadas por esse profissional relacionando-as às funções gerenciais planejamento, organização, direção e controle, a saber: participar da elaboração e organização do planejamento da organização; organizar a realização dos trabalhos na área; participar da distribuição das atividades dos funcionários; supervisionar atividade de funcionários; desenvolver atividades de liderança; avaliar o alcance dos objetivos e metas e acompanhar a realização do planejamento.

Em busca de uma delimitação da área de atuação do secretário executivo como gestor por meio dessas atividades, Barros et al. (2013), ponderam que esse profissional colabora de forma efetiva para o alcance dos objetivos da empresa, por meio da gestão de serviços de secretarial. Corroborando essa ideia Barros, Silva e Ferreira (2015) constataram que o as atividades de gestão secretarial abrangem a organização em seu contexto geral e a área específica secretarial. Tais percepções denotam que a atuação do gestor secretarial é desenvolvida no âmbito das atividades secretariais em sua área de atuação, contribuindo para os resultados organizacionais como um todo.

Silva (2013) propõe que as responsabilidades do secretário executivo estão relacionadas à gestão do conhecimento e de relacionamento situando-o na proposição ética de Habermas (1983), ao identificar que o secretário está em constante inter-relação com as pessoas por meio da ação comunicativa. Afirmou que a ética do Discurso emerge como um ideal para a gestão secretaria partindo do pressuposto de que o secretário executivo deve ser comprometido com a instituição e seus colaboradores.

Percebe-se um esforço das investigações em busca de caminhos investigativos que possibilitem uma melhor compreensão acerca da gestão secretarial. No entanto, conforme alertam Silva, Barros e Barbosa (2012) existe carência de pesquisas que proporcionem um aparato teórico e empírico acerca do tema, visto que as produções são escassas. Assim sendo, ainda há muito a ser investigado para que haja uma definição consubstancial para esse objeto de estudo. 


\section{CONSIDERAÇÕES FINAIS}

De acordo com os trabalhos analisados, percebe-se que os temas dos estudos publicados dizem respeito à concepção do secretário executivo no âmbito da gestão, sendo encontradas variações que destacam: competências do secretário executivo relacionadas à gestão, gestão para assessoria, a concepção de secretário executivo como gestor, atividades do gestor secretarial nas funções administrativas, o secretário executivo como gestor do conhecimento e de relacionamento.

Quanto à questão norteadora deste texto, considera-se que as contribuições das pesquisas se manifestam na interdisciplinaridade da área, mantendo um diálogo com teorias diversas, principalmente da administração, indicando que a gestão secretarial possui estreita relação com as questões administrativas. Os estudos favorecem, ainda, o aprofundamento das discussões, uma vez que contém dados obtidos de pesquisas com secretários executivos que desenvolvem atividades de gestão.

Também se consideram relevantes para delinear a gestão secretarial os estudos abordando as relações interpessoais desenvolvidas na atuação do secretário executivo, mediadas pela inteligência emocional e pela ética, visto que um dos aspectos primordiais no exercício profissional é a observância aos princípios éticos e morais como forma de responder às demandas da sociedade.

Com base nessas constatações, a elaboração deste EQ aponta, como caminho para a continuidade do projeto em andamento, a busca por aportes teóricos e empíricos que possibilitem discutir os aspectos de gestão presentes na atuação do secretário executivo, na perspectiva de que se trata de uma profissão que exige, além dos conhecimentos técnicos específicos e do domínio de ferramentas administrativas, a relação com colaboradores e a sociedade pautados na ética e responsabilidade.

Percebeu-se que existem poucos estudos específicos de gestão secretarial, evidenciando tanto uma lacuna em relação à sua consolidação como área de conhecimento, quanto a necessidade de estabelecer o seu objeto de estudo, a fim de caminhar para o surgimento de uma teoria que comporte um arcabouço teórico-metodológico. Acredita-se que o desenvolvimento do projeto de pesquisa "Gestão secretarial e produção de conhecimento em Secretariado Executivo" trará mais elementos científicos para esse campo, visto que direcionará o olhar para 
a prática profissional observando as diferentes formas de gestão presentes, com amparo em teorias que possibilitem à construção de proposições epistemológicas para a área secretarial.

Poderá ser observado, com base na concepção desse profissional, como o desenvolvimento de suas atribuições de gestão contribuem para o alcance dos objetivos organizacionais, propiciando o estabelecimento de princípios para o delineamento de uma conceituação fundamentada em aspectos teóricos e empíricos para a gestão secretarial.

Conclui-se, portanto, que a elaboração do EQ sobre o objeto desta investigação oportunizou ampla visão acerca do que está sendo pesquisado no estado atual do conhecimento, quais são os principais enfoques dos estudiosos e suas bases de sustentação teóricas e empíricas e, assim, elucidar a contribuição do projeto que está sendo desenvolvido para a produção do conhecimento científico em Secretariado Executivo.

Como limitações deste estudo, vale ressaltar alguns obstáculos no que concerne à elaboração do EQ. O levantamento não conseguiu dispor dos anais de todas as edições dos eventos ENASEC, visto que o site estava em construção para atualização. Assim sendo, o número de trabalhos seria maior se o acesso aos anais tivesse se dado de forma total, abarcando todas as suas edições. Além disso, o site que abriga a Biblioteca Digital Brasileira de Teses e Dissertações (BDTD), que poderia ser uma fonte de coleta complementar, a fim de identificar dissertações e teses sobre a temática, não estava disponível.

Considerando-se a complexidade do tema abordado nesta pesquisa, bem como a necessidade de preencher lacunas científicas acerca do seu objeto, sugere-se que sejam realizadas pesquisas futuras que viabilizem a ampliação e o aprofundamento do EQ, buscando outras bases de dados, como eventos internacionais, revistas de Administração e outras áreas que dialogam com o Secretariado Executivo, bem como o acesso à BDTD.

\section{REFERÊNCIAS}

ALMEIDA, W. G.; ROGEL, G.; SHIMOURA, A. S. Mudanças de paradigmas na gestão do profissional de secretariado. Revista de Gestão e Secretariado, v. 1, n. 1, p. 46-68, 2010.

AKPOMI, M.; ORDU, P. Modern office technology and the secretary's productivity in private business organizations. African Journal of Business Management, v. 3, n. 8, p. 333-339, 2009. Disponível em: <http://www.academicjournals.org/journal/AJBM/articleabstract/1EA0B3517153>. Acesso em: 31 jul. 2018. 
BARDIN, L. Análise de Conteúdo. Lisboa: Edições 70, 2009.

BARROS, C. M. P.; SILVA, J. S..; LIMA, G. A.; BRITO, D. G. S. As competências gerenciais desenvolvidas pelos secretários executivos. Revista de Gestão e Secretariado, v. 4, n. 2, p 2547, 2013. Disponível em: <https://www.revistagesec.org.br/secretariado/article/view/131/pdf_29>. Acesso em: 26 jul. 2018.

BARROS, C. M. P.; BRAGA, M. C.; SILVA, J. S. As competências gerenciais na atuação do secretário executivo no nível estratégico. Revista Expectativa, v. 10, n. 10, p. 91-106, 2011. Disponível em: <http://e-revista.unioeste.br/index.php/expectativa/article/view/6096/4700>. Acesso em: 1 ago. 2018.

BARROS, C. M. P.; SILVA, J. S.; FERREIRA, F. D. Gestão Secretarial: delineando atividades, funções e competências gerenciais. Revista Gestão e Contabilidade da UFPI, v. 2, n. 2, p. 149-171, 2015. Disponível em: <http://www.ojs.ufpi.br/index.php/gecont/article/view/1626>. Acesso em: 25 jul. 2018.

BECKER, G.; CEOLIN, J. Gestão secretarial: uma nova visão de assessoramento nas organizações. Secretariado Executivo em Revista. v. 6, 2010. Disponível em: <http://seer.upf.br/index.php/ser/article/view/2100>. Acesso em: 29 jul. 2018.

BICUDO, M. A. V. A pesquisa qualitativa olhada para além dos seus procedimentos. In:

(Org.). Pesquisa qualitativa segundo a visão fenomenológica. 1. ed. São Paulo: Editora Cortez, 2011. p. 11-28.

BRANDÃO, H. P. Aprendizagem, contexto, competência e desempenho: um estudo multinível. Tese (Doutorado em Psicologia Social, do Trabalho e das Organizações) Universidade de Brasília, Brasília, Brasil. 2009. Disponível em: <http://repositorio.unb.br/handle/10482/8322>. Acesso em: 1 ago. 32018.

Mapeamento de competências: métodos, técnicas e aplicações em gestão de pessoas. São Paulo: Atlas, 2012.

BRASIL. Resolução no 3, de 23 de junho de 2005. Institui as Diretrizes Curriculares Nacionais para o curso de graduação em Secretariado Executivo e dá outras providências. Disponível em: <http://portal.mec.gov.br/component/content/article? id=12991>. Acesso em: 1 ago. 2018.

Portaria $\mathrm{n}^{\circ} 449$, de 30 de maio de 2018. Dispõe sobre o componente específico da área de Secretariado Executivo do Enade 2018. Disponível em: $<$ http://www.imprensanacional.gov.br/materia/- 
/asset_publisher/Kujrw0TZC2Mb/content/id/16917795/do1-2018-06-04-portaria-n-449-de30-de-maio-de-2018-16917775>. Acesso em: 1 ago. 2018.

BRUN, A.; CECHET, G.; NEUMANN, S. Gestão secretarial: a evolução das funções do profissional de secretariado e a efetividade da inteligência emocional nos processos de trabalho. Secretariado Executivo em Revista, v. 8, p. 36-51, 2012. Disponível em: <http://seer.upf.br/index.php/ser/article/view/3024/2030>. Acesso em: 20 jul. 2018.

CABRAL, A. C. A. Reflexões sobre a pesquisa nos estudos organizacionais: em busca da superação da supremacia dos enfoques organizacionais. In: XXII ENCONTRO DA ANPAD. Anais... Foz do Iguaçu, Brasil, Associação Nacional de Pós-Graduação e Pesquisa em Administração, 1998, CD-ROM.

CALDAS, J. B.; SANTOS, M. F. S. As ferramentas da prática da gestão secretarial utilizadas pelos profissionais de secretariado executivo egressos da Universidade do Estado do Pará. Secretariado Executivo em Revista, n. 8, p. 62-74, 2012. Disponível em: <http://seer.upf.br/index.php/ser/article/view/3026>. Acesso em: 20 jul. 2018.

COSTA JÚNIOR, V.; VALÉRIO, J. H. P.; CANTAROTTI, A. As ferramentas da análise SWOT e ciclo PDCA implantadas no contexto da gestão secretarial. Secretariado Executivo em Revista, n. 13, p. 6-19, 2017. Disponível em: <http://seer.upf.br/index.php/ser/article/view/8091/4772>. Acesso em 26 jul. 2018.

DUTRA, J. S. Competências: conceitos e instrumentos para a gestão de pessoas na empresa moderna. São Paulo: Atlas, 2010.

FAYOL, H. Administração Industrial e Geral. 10. ed. São Paulo: Atlas, 1990.

FERREIRA, A. B. H. Mini Aurélio Século XXI escolar. 4 ed. Rio de Janeiro: Nova Fronteira, 2001.

FISCHIMANN, A. A. Planejamento estratégico na prática. 2. ed. São Paulo: Atlas, 2009.

FLEURY, M. T. L; FLEURY A. Construindo o conceito de competência. Revista de Administração Contemporânea. Edição Especial, p. 183-196, 2001. Disponível em: <http://www.anpad.org.br/rac/vol_05/dwn/rac-v5-edesp-mtf.pdf>. Acesso em: 20 jul. 2018

GOLEMAN, D. Inteligência emocional: a teoria revolucionária que redefine o que é ser inteligente. Rio de Janeiro: Objetiva, 1995. 
GONÇALVES, T. D.; COSTA, L. F. A gestão de projetos para o profissional de secretariado. Encontro Nacional dos Estudantes de Secretariado. In: ENCONTRO NACIONAL DOS ESTUDANTES DE SECRETARIADO EXECUTIVO. Anais... Florianópolis, Brasil, Associação Brasileira de Pesquisa em Secretariado, 2016. Disponível em: <http://www.enesec.com.br/vii-enesec2014>. Acesso em: 26 jul. 2018>.

GOODE, W. J.; HATT, P. K. Métodos em pesquisa social. 7 ed. São Paulo: Nacional, 1979.

HABERMAS, J. Para a reconstrução do materialismo histórico. Tradução de Carlos Nelson Coutinho. São Paulo: Brasiliense, 1983.

HALICI, A.; YILMAZ, B.; KASIMOGLU, M. Employment predictions in secretarial occupation. Journal of Management and Sustainability, v. 2, n. 2, p. 187-196, 2012. Disponível em: <http://www.ccsenet.org/journal/index.php/jms/article/view/18181>. Acesso em: 1 ago. 2018.

KAKABADSE, A.; KHAN, N.; KAKABADSE, N. K. Company secretary: a role of breadth and majesty. Society and Business Review, v. 11, n. 3, p. 333-349, 2016. Disponível em: <http://centaur.reading.ac.uk/67555/>. Acesso em: 1 ago. 2018.

LASTA, A.; DURANTE, D. A gestão secretarial no cenário organizacional contemporâneo. Secretariado em Revista, v. 4, 2008. Disponível em: <http://www.upf.br/seer/index.php/ser/article/view/1768>. Acesso em: 26 jul. 2018.

LEAL, F. G.; DALMAU, M. B. L. Análise das competências secretariais requeridas pela universidade federal de Santa Catarina em comparação ao perfil profissiográfico do secretário executivo. Revista de Gestão e Secretariado, v. 5, n. 3, p 143-174, 2014. Disponível em: <https://www.revistagesec.org.br/secretariado/article/view/289>. Acesso em: 26 jul. 2018.

MATITZ, Q. R. S. VIZEU, F. Construção e Uso de Conceitos em Estudos Organizacionais: Por uma Perspectiva Social e Histórica In: XXXIV ENCONTRO DA ANPAD. Anais... Rio de Janeiro, Brasil, Associação Nacional de Pós-Graduação e Pesquisa em Administração, 2010, CD-ROM.

MAXIMIANO, A. A. Introdução à Administração. 6. ed. São Paulo: Atlas, 2004.

MONTENEGRO, N. M. R. M.; DURANTE, D. G. Secretário executivo na gestão: evidências empíricas. In: II ENCONTRO DE ESTUDOS E PESQUISAS EM SECRETARIADO EXECUTIVO. Anais... Fortaleza, Brasil, Universidade Federal do Ceará, 2017. Disponível em: <https://docs.wixstatic.com/ugd/b43479_149da0df06b24a2c8cfe9e8aa48cff53.pdf>. Acesso em: 21 jul. 2018. 
MOTTA, P. R. Gestão contemporânea: a ciência e a arte de ser dirigente. Rio de Janeiro: Record, 1999.

Gestão Contemporânea: a ciência e a arte de ser dirigente. 15. ed. Rio de Janeiro:

Record, 2004.

NASCIMENTO, E. P. Pesquisa aplicada e interdisciplinaridade: da linguística ao secretariado. In: DURANTE, D. G. (Org). A pesquisa em secretariado: cenário, perspectivas e desafios. Passo Fundo: Ed. Universidade de Passo Fundo, 2012.

NÓBREGA-THERRIEN, S. M.; THERRIEN, J. Os trabalhos científicos e o estado da questão: reflexões teórico-metodológicas. Estudos em Avaliação Educacional, v. 15, n. 30, p. 5-16, 2004.

Disponível

em:

<http://publicacoes.fcc.org.br/ojs/index.php/eae/article/view/2148/2105>. Acesso em: 1 ago. 2018.

O estado da questão: aportes teórico-metodológicos e relatos de sua produção em trabalhos científicos. In: FARIAS, I. M. S.; NUNES, J. B. C.; NÓBREGA-TERRIEN, S. M. (Orgs.). Pesquisa científica para iniciantes: caminhando no labirinto. Fortaleza: EdUECE, 2010. p. 33-51.

OLIVEIRA, D. P. R. Estrutura organizacional: uma abordagem para resultados e competitividade. 1. ed. São Paulo: Atlas, 2006.

OLIVEIRA, M. M. Como fazer pesquisa qualitativa. 3. ed. Petrópolis: Vozes, 2010.

PAES, R. V. O.; MERCÊS, F. M. A evolução das técnicas secretariais e da gestão secretarial. In: ENCONTRO NACIONAL DOS ESTUDANTES DE SECRETARIADO EXECUTIVO. Anais... Universidade Federal do Amapá, 2012. v. 01, n. 01, 2012. 167 p. 1 CD-ROM. Disponível em: 〈http://enesec2016.ufsc.br/2016/07/20/anais-do-viii-enesec/>. Acesso em: 1 ago. 2018.

QUINN, R. E.; FEARMAN, S. R.; THOMPSON, M. P.; MCGRATH, M. Competências gerenciais: princípios e aplicações. Rio de Janeiro: Elsevier, 2003.

ROBBINS, S. Administração, mudanças e perspectivas. São Paulo: Saraiva, 2000.

RUAS, R. L. A atividade gerencial no século XXI e a formação de gestores: alguns nexos pouco explorados. Revista Eletrônica de Administração, v. 6, n. 3, p. 2-8, 2000. Disponível em: <https://lume.ufrgs.br/handle/10183/19335>. Acesso em: 1 ago. 2018. 
SANTOS, C. H. S.; OLIVEIRA, S. C. C.; STRADIOTO, J. P.; BERNARDY, R. Gestão de processos: a proposição de um modelo de análise. Contextus: Revista Contemporânea de Economia e Gestão. v. 15, n. 1, p. 84-121, 2017. Disponível em: <http://dx.doi.org/10.19094/contextus.v15i1.926>. Acesso em: 31 jul. 2018.

SANTOS, S. A.; SILVA, J. S. Cenário do ensino da gestão secretarial em cursos de graduação na área de secretariado executivo no Brasil. In: I ENCONTRO DE ESTUDOS E PESQUISAS EM SECRETARIADO EXECUTIVO. Anais... Fortaleza, Brasil, Universidade Federal do Ceará, 2014. Disponível em: 〈https://enepes.wixsite.com/anais/edicoes〉. Acesso em: 31 jul. 2018.

SILVA, R. D. A gestão secretarial na perspectiva da ética discursiva. Dissertação (Mestrado em Ciências Jurídicas e Sociais) - Universidade Federal Fluminense, Niterói, Brasil, 2013. Disponível em: $<$ https://sucupira.capes.gov.br/sucupira/public/consultas/coleta/trabalhoConclusao/viewTrabal hoConclusao.jsf?popup=true\&id_trabalho=89669>. Acesso em: 26 jul. 2018.

SILVA, A. B.; ROMAN NETO, J. Perspectiva multiparadigmática nos estudos organizacionais. In: GODOI, C. K.; BALSINI, C. P; VGODOI, C. K.; BANDEIRA DE MELlO, R.; SILVA, A. B. (Org.). Pesquisa Qualitativa em Estudos Organizacionais. 2. ed. São Paulo: Saraiva, 2010.

SILVA, J. S.; BARROS, C. M. P.; BARBOSA, M. F. S. Fundamentação da gestão secretarial: um estudo bibliométrico. Revista Gestão e Secretariado, n. 2, p. 106-126, 2012. Disponível em: <https://www.revistagesec.org.br/secretariado/article/view/114>. Acesso em: 29 jul. 2018

SILVA, J. S.; BARROS, C. M. P.; CRUZ, R. S. O que você compreende por gestão secretarial? In: IV ENCONTRO NACIONAL ACADÊMICO DE SECRETARIADO. Anais... Londrina, Brasil, Universidade Estadual de Londrina, 2015. Disponível em: <http://abpsec.com.br/ivenasec/anais/anais-do-iv-enasec-encontro-nacional-academico-de-secretariado/>. Acesso em: 23 jan. 2018.

O que se compreende por gestão secretarial: percepção de uma amostra de discentes de secretariado executivo. Revista Gestão em Análise, v. 5, n. 1, p. 65-77, 2016. Disponível em: <http://periodicos.unichristus.edu.br/index.php/gestao/article/view/700>. Acesso em: 31 jul. 2018.

SILVEIRA, C. S..; NÓBREGA THERRIEN, S. M. Estudos sobre pesquisa e formação de professores da Educação Básica: a elaboração do Estado da Questão. Revista Educação em Questão, v. 41, n. 27, p. 219-243, 2011. Disponível em: <https://periodicos.ufrn.br/educacaoemquestao/article/view/4008>. Acesso em: 25 jul. 2018. 
TAGLIARI, M. F. C.; DURANTE, D. G. Gestão secretarial: semelhanças entre competências gerenciais e secretariais. Secretariado Executivo em Revista. v. 5, 2009. Disponível em: <http://seer.upf.br/index.php/ser/article/view/1777/1657>. Acesso em: 1 ago. 2018.

WILLERS, E. M.; BÍSCOLI, F. R. V.; WENNINGKAMP, K.; STABACK, D. F. Mapeamento de competências: mensurando a competência gerencial no desempenho do trabalho de secretários executivos em cargos de chefia numa instituição de ensino superior. In: IV ENCONTRO NACIONAL ACADÊMICO DE SECRETARIADO. Anais... Londrina, Brasil, Universidade Estadual de Londrina, 2015. Disponível em: <http://abpsec.com.br/abpsec/100eventos/115-enasec>. Acesso em: 23 jan. 2018. 